\title{
Structure and function of fish fast skeletal muscle myosin
}

\section{light chains}

\author{
SHOICHIRO ISHIZAKI, ${ }^{1}$ YASUYUKI MASUDA, ${ }^{1}$ MUNEHIKO TANAKA, ${ }^{1}$ AND SHUGO WATABE ${ }^{2}$ \\ 'Department of Food Science and Technology, Tokyo University of Fisheries, Minato, Tokyo 108-8477, Japan \\ (ishizak@tokyo-u-fish.ac.jp), and ${ }^{2}$ Graduate School of Agricultural and Life Sciences, The University of Tokyo, Bunkyo, \\ Tokyo 113-8657, Japan
}

SUMMARY: CDNA clones encoding myosin light chains (A1-, A2-, and DTNB-LC) were isolated from fast skeletal muscles of eight marine teleosts and amino acid sequences were deduced from cDNA nucleotide sequences. The A1-LC from all fish examined was highly conserved in their primary structures as in the case of DTNB-LC and contained a so-called difference peptide of amino acid residues rich in alanine and proline in the $\mathrm{N}$-terminal region, which was absent in A2-LC. However, the N-terminal sequence of fish A2-LC was markedly species-specific. Bottom fish such as walleye pollack and white croaker had conventional A2-LC that lacked the difference peptide. On the other hand, A2-LC from horse mackerel and mackerel-scad showed $\mathrm{N}$-terminal amino acid sequences similar to that of difference peptide, although their peptide length of about 10 residues was much shorter than the conventional difference peptide. Furthermore, sardine and Scombroid fish such as tuna and skipjack contained A2-LC with difference peptide-like sequences of about 21 residues in their $\mathrm{N}$-terminal region. These results imply that $\mathrm{N}$-terminal peptides of A2-LC specific to pelagic fish have physiological functions to facilitate effective swimming in these fish. Such evidence for high A2-LC species-specificity at the molecular level confirmed practical application of LC patterns in various electrophoretic analyses for fish species identification and classification.

\section{KEY WORDS: cDNA cloning, primary structure, fish fast skeletal muscle, myosin light chain}

\section{INTRODUCTION}

Skeletal muscle myosin consists of two heavy chains of approximately $200 \mathrm{kDa}$ and four light chains of approximately $20 \mathrm{kDa}^{1-3)}$ Myosin light chains are located in a region near the junction of myosin head and rod ${ }^{4,5}$ ) and classified into two groups, alkali light chains consisting of two heterologous components (A1 and A2 in the order of decreasing mol. wt) and 5,5'-dithio-bis-2nitrobenzoic acid (DTNB) light chains. ${ }^{1,2)}$ It is known that myosin from fish fast skeletal muscle also possesses four light chains of three different mol. wts. ${ }^{(1)}$ In addition, fish myosin light chains reportedly display greater variability of mol. wt as observed by sodium dodecylsulfatepolyacrylamide gel electrophoresis (SDS-PAGE). ${ }^{6,7)}$ Also, fish myosins can be classified into three types, based on molecular weights of $\mathrm{A} 2$ and DTNB light chains. ${ }^{8-10)}$ However, structural differences responsible for such remarkable species-specificity are unknown. In this study, nucleotide sequences of myosin A1, A2, and DTNB light chains from eight marine teleosts were determined by cDNA cloning. Since the nucleotide sequences of fish fast skeletal muscle myosin light chains had been presented only from carp, ${ }^{11.12)}$ our results are the second reported for complete myosin light chain sequences of fish origin. A sequence of DNA complementary to mRNA encodes a protein with corresponding amino acid sequence. In order to characterize such species-specificity of fish myosin light chains, we compared primary structures of myosin light chains among fish species.

\section{PRIMARY STRUCTURE OF FISH FAST SKELETAL MYOSIN DTNB LIGHT CHAIN}

At first, cDNA clones encoding myosin DTNB light chain were obtained from all fish species examined. After subcloned into a pBluescript vector, nucleotide sequences were analyzed and then amino acid sequences were deduced. Figure 1 shows comparison of deduced amino acid sequences of myosin DTNB light chains from eight fish species. Although data of total DNA nucleotide sequences of all fish species examined were not shown, those of skipjack Katsuwonus pelamis, bluefin tuna Thunnus thynnus, sardine Sardinops melanostictus, anchovy Engraulis japonica, horse mackerel Trachurus trachurus, mackerel-scad Decapterus maruadsi, walleye pollack Theragra chalcogramma, and white croaker Argyrosomus argentatus have already been registered to 


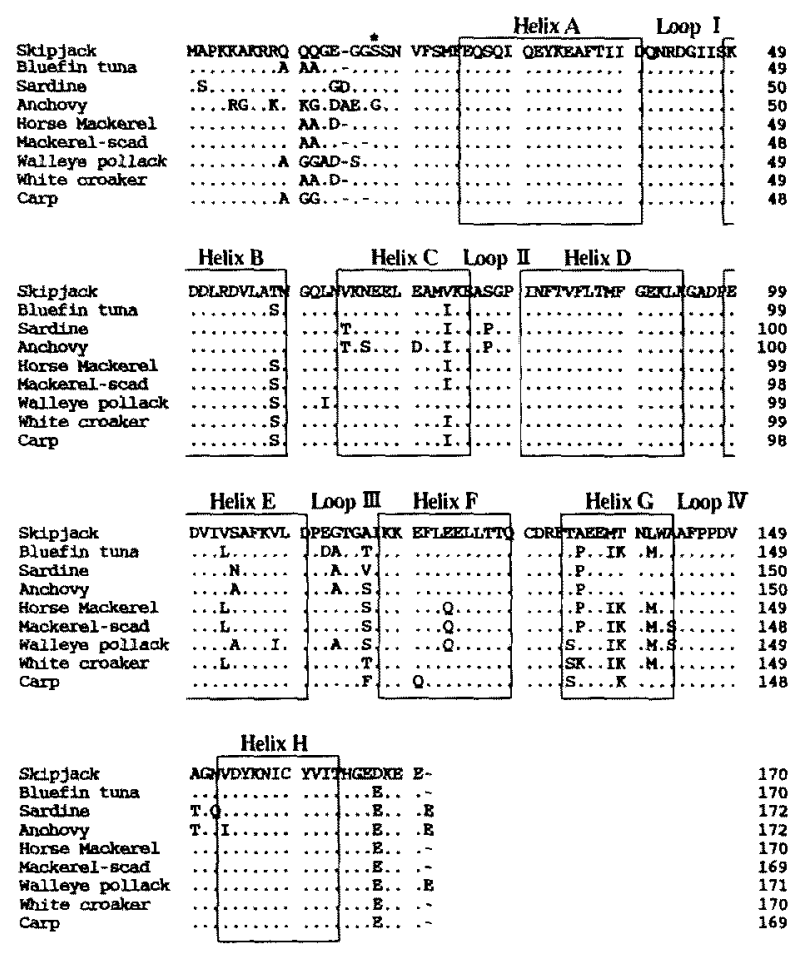

Fig.1. Alignment of deduced amino acid sequences of fast skeletal muscle myosin DTNB light chain from various marine teleosts. Identical amino acid residues are shown by periods; and gaps are represented by dashed lines. Data for comparison was cited from capp. ${ }^{12}$ The putative myosin light chain kinase phosphorylation site is indicated by an asterisk.

the DDBJ/EMBL/GenBank DNA databases with accession numbers of AB042039, AB042036, AB042051, $\mathrm{AB} 042053, \mathrm{AB} 042048$, and $\mathrm{AB} 042042$, respectively. $\mathrm{As}$ a result, amino acid sequences of about 170 residues of DTNB light chains were deduced from cDNA nucleotide sequences of all fish species. Comparison of primary structures of fish myosin DTNB light chains revealed high conservation among species, including carp, resulting in more than 95\% homology among fish species (data not shown). In addition, the fast skeletal muscle DTNB light chain, the so-called regulatory light chain, of higher vertebrates was found to be phosphorylated by myosin light chain kinase both in vivo and in vitro at Ser-15. 13,14) This serine residue was also conserved in fish skeletal muscle DTNB light chains except in anchovy. The DTNB light chain is a member of the EF hand superfamily, which includes calmodulin and troponin- $\mathrm{C}$, consisting of eight helices and four loops. ${ }^{15)}$ It has been demonstrated that Loop I in the first EF hand motif of DTNB light chain retains $\mathrm{Mg}^{2+}$ - binding ability. ${ }^{1\left({ }^{1}\right)}$ It was also noted that amino acid sequences of Loop I were identical among fish fast skeletal muscle DTNB light chains.

\section{PRIMARY STRUCTURE OF FISH FAST SKELETAL MYOSIN AI LIGHT CHAIN}

Figure 2 shows comparison of deduced amino acid

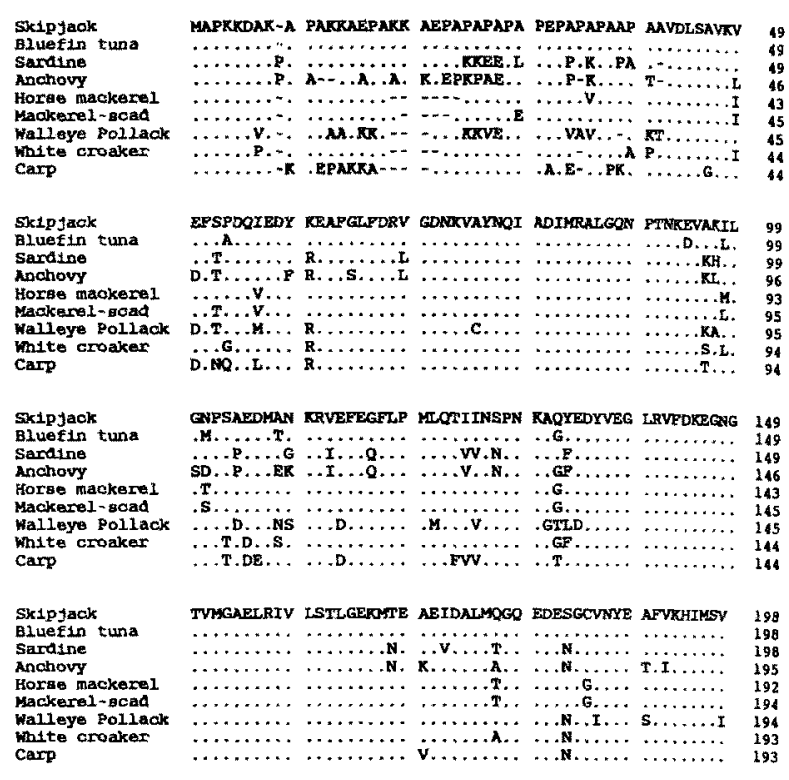

Fig.2. Alignment of deduced amino acid sequences of fast skeletal muscle myosin A1 light chain from various marine teleosts. Identical amino acid residues are shown by periods; and gaps are represented by dished lines. Data for comparison was cited from carp. il?

sequences of myosin $\mathrm{A} 1$ light chain among fish species. Data of total DNA nucleotide sequences of skipjack, bluefin tuna, sardine, horse mackerel, and white croaker have been also registered to the DDBJ/EMBL/GenBank DNA databases with accession numbers of $A B 042037$, $\mathrm{AB} 042034, \mathrm{AB} 042049, \mathrm{AB} 042052, \mathrm{AB} 042046$, $\mathrm{AB} 042054$, and $\mathrm{AB} 042040$, respectively. As shown in Fig. 2, the numbers of amino acid residues of A1 light chains from marine fish were in range of between 192 and 198. Amino acid sequences of A1 light chains from all fish examined were less conserved than those of DTNB light chains. It is well known that primary structures of A1 light chain from rabbit, ${ }^{17)}$ chicken ${ }^{18)}$ or carp ${ }^{11)}$ each show a 'difference peptide' of 41 amino acid residues in $\mathrm{N}$-terminal regions, where $\mathrm{Ala}$, Pro, and Lys are abundant. Similar results, showing an additional peptide (so-called 'difference peptide') of about 40 residues rich in Ala and Pro at the $\mathrm{N}$-terminal, were obtained in sequences of all fish determined. It has already been reported that the Al light chain $\mathrm{N}$-terminal region, especially the difference peptide, interacts with actin. ${ }^{19)}$ However, our results imply that precise peptide length is not crucial for interaction with actin.

\section{PRIMARY STRUCTURE OF FISH FAST SKELETAL MYOSIN A2 LIGHT CHAIN}

Figure 3 shows amino acid sequences of myosin A2 light chains from various fish muscles deduced from $\mathrm{CDNA}$ nucleotide sequences. Data of total DNA nucleotide sequences of skipjack, bluefin tuna, sardine, horse 

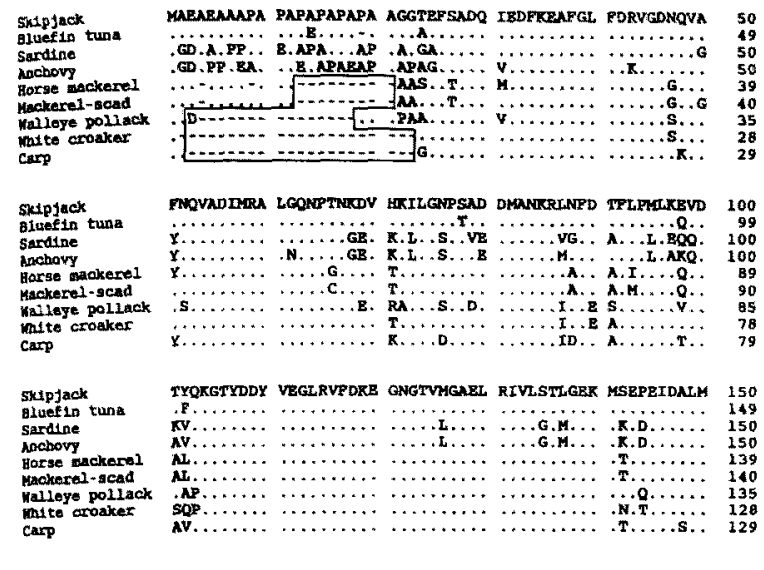

TGOEDENGSV GYBAFVKRIM SV

Blue Elin tur

sacerse

Bcrse anckerel

Halleye pollacio

minte aroaker
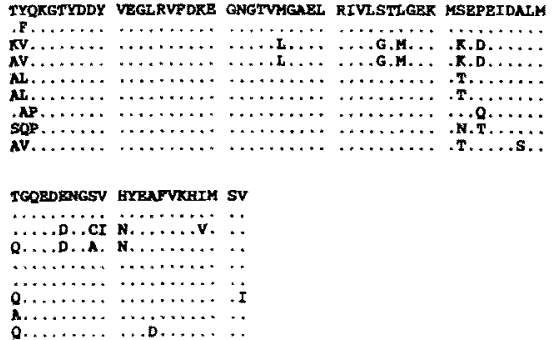

172
171
172
172
161
162
157
150
151

Fig3. Alignment of deduced amino acid sequences of fast skeletal muscle myosin A2 light chain from various marine teleosts. Identical amino acid residues are shown by periods; and gaps are represented by dashed lines. Data for comparison was ciled from carp. ${ }^{11)}$

mackerel, and white croaker have been also registered to the DDBJ/EMBL/GenBank DNA databases with accession numbers of $\mathrm{AB} 042038, \mathrm{AB} 042035, \mathrm{AB} 042050$, $\mathrm{AB} 042047$, and $\mathrm{AB} 042041$, respectively. As shown in this figure, the $\mathrm{N}$-terminal sequence of $\mathrm{A} 2$ light chain was found to be markedly species-specific. Bottom fish, such as walleye pollack and white croaker, had a conventional A2 light chain consisting of 157 and 150 amino acid residues which lacked the difference peptide portion that was detected in A1 light chain. On the other hand, in scombroid and clupeoid fish such as skipjack, bluefin tuna, sardine, and anchovy, distinctive addition of 20-21 amino acid residues was detected in an extreme $\mathrm{N}$-terminal region and the total number of residues was about 172 . Furthermore, in carangoid fish such as horse mackerel and mackerel-scad, additional amino acid comprised only about 9 residues in the $\mathrm{N}$-terminal region and the total number were about 162 residues. These results suggest that the N-terminal peptides of $\mathrm{A} 2$ light chain specific to pelagic fish have physiological functions to facilitate these fish swimming effectively. Such differences in A2 light chain primary structure are supposed to be at least partially attributable to significant species-specificity of fish myosin light chains in SDS-PAGE patterns. ${ }^{6,8)}$ It is also noteworthy from the viewpoint of species authenticity that amino acid sequences of myosin A2 light chains differ among fish species, especially in their N-terminal regions.

It is known that fast skeletal myosin $\mathrm{A} 1$ and $\mathrm{A} 2$ light chains of mammalian and avian species are produced from a single gene by altemative transcription and two modes of splicing. ${ }^{2(1-22)}$ The A2 light chain sequence is

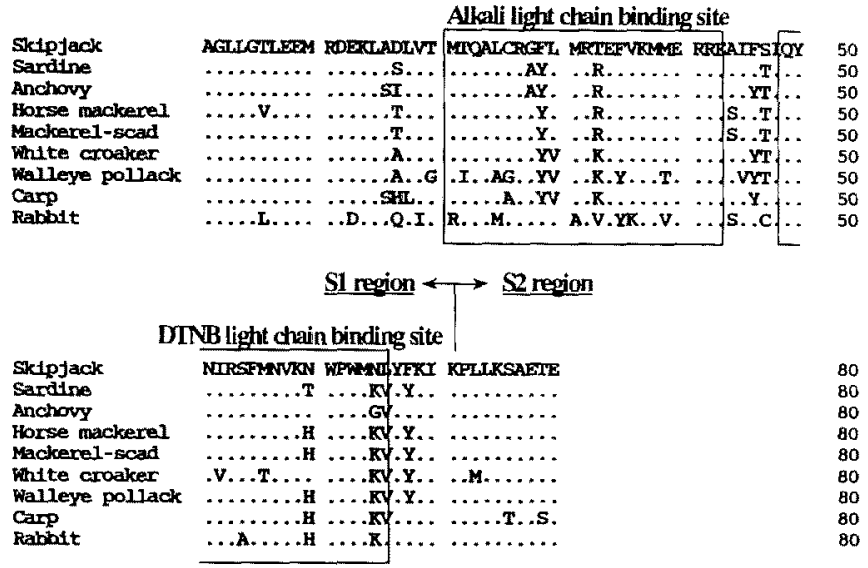

Fig.4. Alignment of deduced amino acid sequences of partial heavy meromyosin including myosin light chain binding site from various marine teleosts. Identical amino acid residues are shown by periods. Data for comparison was cited from white croaker, ${ }^{24)}$ walleye pollack, ${ }^{29}$ carp $^{20}$ and rabbit (GenBank/EMBLDDBJ accession number U32574)

identical with that of C-terminal two-thirds of A1 light chain. However, it has recently been claimed that two myosin alkali light chains of fish fast skeletal muscles from mullet ${ }^{23)}$ and carp $^{11)}$ originate from two different genes in contrast with those of mammalian and avian species. As shown in Figs. 2 and 3, comparison of primary structures of A1 and A2 light chains in all fish species examined also indicated that differences are found over the $\mathrm{C}$-terminal region, where $\mathrm{A} 1$ and $\mathrm{A} 2$ light chains of higher vertebrates share an identical sequence. These results with marine fish are consistent with those reported for mullet and carp, confirming that fish fast alkali light chains are produced from different genes.

\section{COMPARISON OF PRIMARY STRUCTURE OF THE MYOSIN LIGHT CHAIN BINDING SITE IN MYOSIN HEAD}

Electron microscopy studies located light chains in the neck region of myosin molecule. ${ }^{4,5}$ Fish A2 light chain was shown to have about two-fold higher affinity for heavy chains than the A1 light chain; and fish myosin $\mathrm{S} 1(\mathrm{~A} 2)$ isozyme, which was $\mathrm{S} 1$ associated with $\mathrm{A} 2$ light chain only, was more thermostable than $\mathrm{S} 1(\mathrm{~A} 1)^{27)}$ In order to investigate the relationship between high speciesspecificity in alkali light chain among fish and myosin heavy chain, we further determined the primary structure of the myosin head region containing both alkali and DTNB light chain binding sites and then aligned sequences among fish species and rabbit. From the result of Fig.4, relatively lower sequence conservation was seen in the alkali light chain binding region than in the DTNB light chain binding region. Furthermore, substitutions of amino acids seem to differ among four groups: bottom fish, carangoid fish, scombroid and clupeoid fish, and 
mammalian, as detected with comparison of A2 light chain primary structures (Fig. 3). Differences in the $\mathrm{N}$-terminal region of $\mathrm{A} 2$ light chain among fish species may result in differences in interaction between A2 light chain and the motor domain in myosin heads of various origins and therefore in different structural stability of myosin head.

\section{ACKNOWLEDGMENTS}

Live specimen of skipjack, horse mackerel and mackerel-scad, sardine and anchovy, and bluefin tuna were kindly supplied by Mr. M. Terayama, The Miyazaki Prefectural Fisheries Experimental Station, Mr. K. Usui, and Mr. M. Ikeda, Tokyo Sea Life Park, respectively. This study was partly supported by a Grant-in Aid from the Ministry of Education, Science, Sports and Culture of Japan.

\section{REFERENCE}

1. Gaetjens E, Himmelfarb S, Harrington WF. Studies on the subunit structure of myosin.J. Biol. Chem. 1968; 245:15-22.

2. Gazith J, Barany K, Bailin G, Oppenheimer H, Barany M. Studies on the low molecular weight protein components in rabbit skeletal myosin. Archs Biochem. Biophys. 1970; 123:82-96.

3. Weeds AG, Lowey S. Substructure of myosin molecule-II. The light chains of myosin. J. MoL Biol. 1971; 61:701-725.

4. Flicker E, Wallimann T, Vibert P. Electron microscopy of scallop myosin. Location of regulatory light chain. J. Mol. Biol. 1983; 169:723-741.

5. Tokunaga M, Suzuki M, Saeki K, Wakabayashi T. Position of the amino terminus of myosin light chain 1 and light chain 2 determined by electron microscopy with monoclonal antibody. J. Mol. Biol. 1987; 194:245-255.

6. Watabe $S$, Ochiai $Y$, Hashimoto $K$. Identification of 5,5'-dithio-bis-2-nitrobenzoic acid (DTNB) and alkali light chains of piscine myosin. Nippon Suisan Gakkaishi 1982; 48:827-832.

7. Focant B, Huriaux F. Light chains of carp and pike skeletal muscle myosins. Isolation and characterization of the most anodic light chain on alkaline $\mathrm{pH}$ electrophoresis. FEBS Lett. 1976; 65:16-19.

8. Focant B, Huriaux F, Johnston IA. Subunit composition of fish myofibrils: the light chains of myosin. 1976; Int. J. Biochem. 7:129-133.

9. Ochiai Y, Watabe S, Hashimoto K. Physicochemical and immunological properties of myosin light chains from the ordinary muscle of marine teleost fishes. Comp. Biochem. Physiol. 1988; 90B:347-353.

10. Ochiai $\mathrm{Y}$, Kobayashi T, Handa A, Watabe S, Hashimoto $\mathrm{K}$. Immunological cross-reactivity of myosin light chains from various species of fish. Nippon Suisan Gakkaishi 1989; 55:2151-2156.

11. Hirayama $Y$, Kanoh S, Nakaya M, Watabe S. The two essential light chains of carp fast skeletal myosin, LC1 and LC3, are encoded by distinct genes and change their molar ratio following temperature acclimation. J. Exp. Biol. 1997; 200: 693-701.
12. Hirayama $\mathrm{Y}$, Kobiyama A, Ochiai $\mathrm{Y}$, Watabe S. Two types of mRNA encoding myosin regulatory light chain in carp fast skeletal muscle differ in their 3' non-coding regions and expression pattems following temperature acclimation. $J$. Exp. Biol. 1998; 201: 2815-2820.

13. Perrie WT, Smillie LB, Perry SJ. A phosphorylated light-chain component of myosin from skeletal muscle. Biochem. J. 1973; 135:151-164.

14. Sweeney HL, Stull JT. Alteration of cross-bridge kinetics by myosin light chain phosphorylation in rabbit skeletal muscle: implications for regulation of actin-myosin interaction. Proc. Natl. Acad. Sci U.SA. 1990; 87: 414-418.

15. Trybus KM. Role of myosin light chains. J. Muscle Res. Cell Motil. 1994; 15:587-594.

16. DaSilva ACR, Reinach FC. Calcium binding induces conformational changes in muscle regulatory proteins. Trends Biochem. Sci. 1991; 16:53-57.

17. Frank G, Weeds AG. The amino-acid sequences of the alkali light chains of rabbit skeletal-muscle myosin. Eur. J. Biochem. 1974; 44: 317-334.

18. Matsuda $G$, Maita $T$, Umegane $Y$. The primary structure of L-1 light chain of chicken fast skeletal muscle myosin and is genetic implication. FEBS Lett. 1981; 126: 111-113.

19. Yamamoto $\mathrm{K}$, Sekine $\mathrm{T}$. Interaction of alkali light chain 1 with actin: Effect of ionic strength on the cross-linking of alkali light chain 1 with actin. J. Biochem. 1983; 94:2075-2078.

20. Nabeshima $Y$, Fujii-Kuriyama $Y$, Muramatsu $M$, Ogata $K$, Alternative transcription and two modes of splicing result in two myosin light chains from one gene. Nature 1984; 308:333-338.

21. Robert B, Daubas P, Akimento MA, Cohen A, Gamer I, Guenet JL, Buckingham M. A single locus in the mouse encodes both myosin light chains 1 and 3 , a second locus corresponds to a related pseudogene. Cell 1984; 39:129-140.

22. Periasamy $M$, Strehler EE, Garfinkel Ll, Gubits RM, Ruiz-Opazo N, Nadel-Ginard B. Fast skeletal muscle myosin light chains 1 and 3 are produced from a single gene by a combined process of differential RNA transcription and splicing. J. Biol. Chem. 1984; 259:13595-13604.

23. Dalla Libera L, Carpene E, Theibert J, Collins JH. Fish myosin alkali light chains originate from two different genes. J. Muscle Res. Cell Motil. 1991; 12:366-371.

24. Yoon SH, Kakinuma M, Hirayama Y, Yamamoto T, Watabe S. cDNA cloning of myosin heavy chain from white croaker fast skeletal muscle and characterization of its complete primary structure. Fisheries Sci. 2000; 66:1163-1171.

25. Ojima $T$, Kawashima $N$, Inoue $A$, Amauchi $A$, Togashi $M$, Watabe S. Nishita K. Determination of primary structure of heavy meromyosin region of walleye pollack myosin heavy chain by cDNA cloning. Fisheries Sci. 1998; 64:812-819.

26. Imai J, Hirayama $Y$, Kikuchi K, Kakinuma M, Watabe $S$. cDNA cloning of myosin heavy chain isoforms from carp fast skeletal muscle and their gene expression associated with temperature acclimation. J. Exp. Biol. 1997; 200:27-34.

27. Ochiai $Y$, Kobayashi $T$, Handa $A$, Watabe $S$; Hashimoto $K$. Possible presence of the difference peptide in alkali light chain 1 of fish fast skeletal myosin. Comp. Biochem. Physiol. 1990; 97B:793-801. 